\title{
A new account of the conditioning bias to out-groups
}

\author{
Junhua Dang ${ }^{1}$, Shanshan Xiao ${ }^{2}$ and Lihua Mao ${ }^{2 *}$ \\ ${ }^{1}$ Department of Psychology, Lund University, Lund, Sweden \\ 2 Department of Psychology, Peking University, Beijing, China \\ *Correspondence: lihuamao@pku.edu.cn \\ Edited by: \\ Andrew C. Gallup, State University of New York at Oneonta, USA \\ Reviewed by: \\ Ottmar Volker Lipp, University of Queensland, Australia
}

Keywords: conditioning bias, in-group favoritism, out-group derogation, prepared learning, latent inhibition

\section{THE CONDITIONING BIAS TO OUT-GROUPS}

In classical fear conditioning, a neutral stimulus, once paired with an aversive event for several times, can induce fear reaction by itself. Compared with fear-irrelevant stimuli such as birds and butterflies, fear-relevant stimuli such as spiders and snakes are more readily associated with aversive events. This prepared learning phenomenon is highly resistant to extinction, insensitive to cognitive manipulations, and could be acquired in only one trial (Seligman, 1971; Öhman and Mineka, 2001). From an evolutionary perspective, human beings and non-human primates are predisposed to learn to fear spiders and snakes because such preparedness conferred a selective advantage to our ancestors over conspecifics that were not prepared.

Inspired by recent studies that showed overlapping neural systems underlying racial bias and fear conditioning (Phelps et al., 2001; Olsson and Phelps, 2004; Olsson et al., 2005), tested whether prepared learning can be extended to a socio-cultural context. They employed the differential conditioning paradigm that consisted of three phases-habituation, acquisition, and extinction - presented in sequence (Öhman and Mineka, 2001). The conditioned stimuli (CS) were two pictures of Black individuals and two pictures of White individuals. During habituation, all pictures were presented without reinforcement. During acquisition, one of the pictures from each race (CS+) was accompanied by an electric shock (the unconditioned stimulus, US), whereas the other (CS-) was not. During extinction, no shocks were administered.
The conditioned fear response (CR) was obtained by subtracting participants' skin conductance responses (SCRs) to the CSfrom their SCRs to the CS+ for each race. The main result was that the CR to racial out-group faces persisted whereas the $\mathrm{CR}$ to in-group faces was fully extinguished in the absence of the US.

\section{AVAILABLE EXPLANATIONS AND THEIR SHORTAGES}

The finding for racial faces resembles the pattern observed for spiders and snakes, indicating that racial out-group faces may serve as a signal of social threat and be processed in a manner similar to fearrelevant stimuli. However, it may be too early to conclude that the conditioning bias to out-groups could be considered as a typical prepared learning phenomenon. Theoretically, the evidence that human populations differentiated into different races recently in evolutionary history because of geographic isolation of different lineages makes it unlikely that humans could have evolved mechanisms specifically to learn to fear different races, since being genetically prepared to learn to fear other races could not provide any selective advantage (Maia, 2009). In the meantime, to be regarded as an instance of prepared learning, an association has to fulfill not only the criterion of resistance to extinction, but also the criteria of one trial learning and insensitivity to cognitive manipulations. However, researchers have found that the conditioning bias to out-groups was abolished by cognitive manipulations. During the extinction phase, such bias disappeared once the experimenter informed participant that no more electric shocks would be presented and the shock electrode was removed from participants' arm (Mallan et al., 2009).

Recently, a theoretical analysis argued that the conditioning bias to out-groups could be explained by standard learning theory (Maia, 2009). Specifically, the author suggested that the conditioning bias to out-groups might be mediated by a mechanism called latent inhibition. That is to say, a familiar but unassociated stimulus takes longer to acquire meaning (as a signal) than a new stimulus. In the intergroup context, people are generally familiar with their in-groups, so they need more time to associate their in-groups with the unconditioned stimuli. During the same acquisition time, this association would not become so strong as the association between the unfamiliar out-groups and the unconditioned stimuli. As a result, it would also be easier to extinguish. The pattern of Olsson et al.'s (2005) findings was indeed consistent with this account. Besides the finding that the $\mathrm{CR}$ to outgroups remained significant after extinction, the CR to out-groups also appeared to be stronger than the $\mathrm{CR}$ to in-groups during acquisition, although no explicit comparison was done in Olsson et al.'s (2005) study.

In our opinion, although it is not appropriate to consider the conditioning bias to out-groups as preparedness and use the evolutionary account to explain it, the latent inhibition view does not provide a convictive explanation, either. For example, a very recent research using the minimal group paradigm found that after arbitrarily assigned to different groups according to a trivial criterion (e.g., perceptual style), participants more readily learned a fear response when an aversive 
stimulus was paired with out-group faces than when it was paired with in-group faces (Navarrete et al., 2012). That is to say, the CR to out-groups was stronger than the $\mathrm{CR}$ to in-groups during acquisition. However, unlike Olsson et al.'s (2005) results, the CRs to both in-groups and outgroups were fully extinguished during the extinction phase. Latent inhibition could not explain why the CR to out-groups were stronger than the $\mathrm{CR}$ to in-groups in that the two groups were both formed in the lab, having little difference in their familiarity, and thus should not result in different learning rate.

Indeed, Olsson et al. (2005) also questioned the evolutionary account but instead argued that sociocultural learning about the identity and qualities of out-groups provided the basis for persistence of the CR to out-groups. That is to say, repeated exposure to negative information about out-groups might prepare people to fear newly encountered out-group members. Similar idea has also been advanced by other researchers very recently (Mallan et al., 2013). This account seems evolutionarily more plausible and has a potential to reconcile the extinguished CR to out-groups in the minimal group paradigm (Navarrete et al., 2012). However, these researchers did not elaborate the specific underlying mechanism. In the meanwhile, this account still has a limitation to explain the reduced CR to ingroups during acquisition (Olsson et al., 2005; Navarrete et al., 2012).

\section{A NEW ACCOUNT}

We think in order to provide a more complete explanation, we have to take into account the theories and findings in the area of intergroup relationship. Traditionally, research in this field appeared to accept, at least implicitly, the idea that relationships between ingroups and out-groups were characterized by antagonism, conflict, and mutual contempt. As a result, the favoritism toward in-groups and the derogation toward outgroups were studied interchangeably, as if they were two sides of the same coin. Recently, more and more researchers began to re-consider this issue and suggested in-group favoritism and out-group derogation were separable phenomena (e.g., Brewer, 1999; Hewstone et al., 2002).
For example, most minimal group studies rating the in-group and the out-group separately found that categorization into groups led to positive in-group ratings in the absence of negative out-group ratings (Brewer, 1979). Further, the positive in-group bias found in the allocation of positive resources (e.g., money) using the minimal group paradigm disappeared when negative outcomes (e.g., noise) were distributed (e.g., Mummendey et al., 1992), suggesting humans are willing to differentially benefit the in-groups rather than harm out-groups. Recent research in developmental psychology (e.g., Aboud, 2003) and social neuroscience (e.g., Van Bavel et al., 2011) provided further supporting evidence for this perspective. Indeed, researchers even found that group formation and positive in-group regard had intragroup origins and did not require comparison with a contrasting out-group (Gaertner et al., 2006).

According to this new perspective, in-group favoritism arises from a selfanchoring mechanism such that selfevaluation could automatically extend to in-groups. As recent research revealed, personal trait self-esteem is positively correlated with in-group favoritism and this association holds not only when the ingroup and the out-group are equivalent (i.e., classed only by a trivial criteria) but also when the in-group is objectively less favorable than the outgroup (Gramzow and Gaertner, 2005). Because people generally have a good view of themselves, they would automatically transfer such positivity to the perception regarding their in-groups. For example, using a typical paradigm measuring spontaneous trait inferences in a minimal group setting, Otten and Moskowitz (2000) demonstrated that behaviors that implied positive traits about an in-group member were more likely to be categorized in a manner consistent with the implied trait. However, there was no facilitation of trait inference to out-group members performing negative behaviors, suggesting there was evidence for implicit in-group favoritism but not out-group derogation.

In contrast, out-group derogation occurs when the very existence of the out-group, or its goals and values, are seen as a threat to the maintenance and the social identity of the in-group (Brewer, 2007). The integrated threat theory (Stephan and Stephan, 2000) distinguishes four different sources of experienced threat from a specific outgroup: realistic threat (threat to in-group physical and psychological well-being), symbolic threat (threat to the stability of in-group values and beliefs), intergroup anxiety (personal discomfort arising from actual or anticipated interactions with outgroups), and negative stereotypes (beliefs about out-group characteristics implying unfavorable interactions and negative consequences). Following studies supported this model by showing that these threat perceptions (especially the first three perceptions) significantly predicted negative attitudes toward out-groups and mediated the effects of other predictors such as intergroup contact (Stephan et al., 2002).

Thus, the conditioning bias to outgroups may relate to the mechanism underlying in-group favoritism and outgroup derogation. On one hand, since individuals tend to automatically transfer the positive view of themselves to their in-groups, either novel ones (e.g., formed arbitrarily in a lab) or real ones (e.g., Blacks or Whites), their in-groups would be rated more positively than their out-groups. When in-group faces and out-group faces serve as CS, in-group faces, initially positive stimuli, would need more time to acquire an aversive meaning (Zanna et al., 1970). Consequently, the $\mathrm{CR}$ to in-group faces would be weaker than the CR to out-group faces during the acquisition phase. Such inferences are indeed consistent with both Olsson et al.'s (2005) findings (using racial groups) and Navarrete et al.'s (2012) findings (using minimal group paradigm).

On the other hand, out-groups would generally be rated neutral if the outgroup does not pose a threat to the in-group. Previous research revealed that the $\mathrm{CR}$ to fear-irrelevant neutral stimuli could be extinguished during the extinction phase (Seligman, 1971). That is also what Navarrete et al. (2012) found in a minimal group setting. However, under certain conditions (e.g., when high conflict between groups occurs), out-groups would be rated negatively because they are perceived as a threat to in-groups. In Olsson et al.'s (2005) study, they used 
two racial groups, Whites and Blacks. Obviously, these two racial groups shared a history of discrimination, prejudice, and even war. The racial issue is still sensitive and tense in today's America and both groups hold a negative attitude toward each other. Since fear responses to CS that already have a negative valence are easier to acquire (Zanna et al., 1970) and thus harder to extinguish, there is no wonder that these authors found the CR to outgroups failed to be extinguished. Although this analysis shares some features with the sociocultural learning process proposed by Olsson et al. (2005) and Mallan et al. (2013), it provides more details and specifies when and how the CR to out-groups persists.

Certainly, this account needs to be tested empirically. We think there are three initial ways to do it. First, future studies could examine it using real groups (e.g., racial groups) by adding measures of in-group favoritism and outgroup derogation. We predict in-group favoritism would be negatively correlated with the $\mathrm{CR}$ to in-groups during acquisition whereas out-group derogation would be positively correlated with the CR to out-groups during both acquisition and extinction. Second, since ingroup love is the extension of people's personal self-esteem, it is natural to infer that weaker CR to in-groups during acquisition would occur only for individuals with higher self-esteem. State self-esteem could be manipulated to test this hypothesis. Third, we could also adapt the minimal group paradigm by manipulating the relationship between in-groups and outgroups. Our hypothesis is that if there is a conflict between arbitrarily assigned groups, the conditioning bias, just as what Olsson et al.'s (2005) reported using racial groups (i.e., stronger CR to out-groups during acquisition and remaining $C R$ to out-groups during extinction), would be found.

\section{FUNDING}

This work was supported by National Basic Research Program of China (973 Program 2015CB351800).

\section{ACKNOWLEDGMENT}

We sincerely thank Fredrik Björklund for providing suggestions for the early version of the manuscript.

\section{REFERENCES}

Aboud, F. E. (2003). The formation of in-group favoritism and out-group prejudice in young children: are they distinct attitudes? Dev. Psychol. 39, 48-60. doi: 10.1037/0012-1649. 39.1 .48

Brewer, M. B. (1979). In-group bias in the minimal intergroup situation: a cognitivemotivational analysis. Psychol. Bull. 86, 307-324. doi: 10.1037/0033-2909.86.2.307

Brewer, M. B. (1999). The psychology of prejudice: ingroup love or outgroup hate? J. Soc. Issues 55, 429-444. doi: 10.1111/0022-4537.00126

Brewer, M. B. (2007). The importance of being we: human nature and intergroup relations. Am. Psychol. 62, 728-738. doi: 10.1037/0003066X.62.8.728

Gaertner, L., Iuzzini, J., Witt, M. G., and Oriña, M. M. (2006). Us without them: evidence for an intragroup origin of positive in-group regard. J. Pers. Soc. Psychol. 90, 426-439. doi: 10.1037/00223514.90.3.426

Gramzow, R. H., and Gaertner, L. (2005). Self-esteem and favoritism toward novel in-groups: the self as an evaluative base. J. Pers. Soc. Psychol. 88, 801-815. doi: 10.1037/0022-3514.88.5.801

Hewstone, M., Rubin, M., and Willis, H. (2002). Intergroup bias. Annu. Rev. Psychol. 53, 575-604. doi: 10.1146/annurev.psych.53.100901.135109

Maia, T. V. (2009). Fear conditioning and social groups: statistics, not genetics. Cogn. Sci. 33, 1232-1251. doi: 10.1111/j.1551-6709.2009. 01054.x

Mallan, K. M., Lipp, O. V., and Cochrane, B. (2013). Slithering snakes, angry men and out-group members: what and whom are we evolved to fear? Cogn. Emot. 27, 1168-1180. doi: 10.1080/02699931.2013.778195

Mallan, K. M., Sax, J., and Lipp, O. V. (2009). Verbal instruction abolishes fear conditioned to racial out-group faces. J. Exp. Soc. Psychol. 45, 1303-1307. doi: 10.1016/j.jesp.2009.08.001

Mummendey, A., Simon, B., Dietze, C., Grunert, M., Haeger, G., Kessler, S., et al. (1992). Categorization is not enough: intergroup discrimination in negative outcome allocations. J. Exp. Soc. Psychol. 28, 125-144. doi: 10.1016/0022-1031(92) 90035-I

Navarrete, C. D., McDonald, M. M., Asher, B. D., Kerr, N. L., Yokota, K., Olsson, A., et al. (2012). Fear is readily associated with an out-group face in a minimal group context. Evol. Hum. Behav. 33, 590-593. doi: 10.1016/j.evolhumbehav. 2012. 02.007

Öhman, A., and Mineka, S. (2001). Fears, phobias and preparedness: toward an evolved module of fear and fear learning. Psychol. Rev. 108, 483-522. doi: 10.1037/0033-295X.108.3.483
Olsson, A., Ebert, J., Banaji, M., and Phelps, E. (2005). The role of social groups in the persistence of learned fear. Science 309, 785-787. doi: 10.1126/science.1113551

Olsson, A., and Phelps, E. A. (2004). Learned fear of "unseen" faces after Pavlovian, observational, and instructed fear. Psychol. Sci. 15, 822-828. doi: 10.1111/j.0956-7976.2004.00762.x

Otten, S., and Moskowitz, G. B. (2000). Evidence for implicit evaluative in-group bias: affect-biased spontaneous trait inference in a minimal group paradigm. J. Exp. Soc. Psychol. 36, 77-89. doi: 10.1006/jesp.1999.1399

Phelps, E. A., O’Connor, K. J., Gatenby, J. C., Gore, J. C., Grillon, C., and Davis, M. (2001). Activation of the left amygdala to a cognitive representation of fear. Nat. Neurosci. 4, 437-441. doi: 10.10 $38 / 86110$

Seligman, M. (1971). Phobias and preparedness. Behav. Ther. 2, 307-320. doi: 10.1016/S00057894(71)80064-3

Stephan, W. G., Boniecki, K. A., Ybarra, O., Bettencourt, A., Ervin, K. S., Jackson, L. A., et al. (2002). The role of threats in the racial attitudes of blacks and whites. Pers. Soc. Psychol. Bull. 28, 1242-1254. doi: 10.1177/0146167202 2812009

Stephan, W. G., and Stephan, C. W. (2000). "An integrated threat theory of prejudice," in Reducing Prejudice and Discrimination, ed S. Oskamp (Mahwah, NJ: Erlbaum), 23-45.

Van Bavel, J. J., Packer, D. J., and Cunningham, W. A. (2011). Modulation of the fusiform face area following minimal exposure to motivationally relevant faces: evidence of in-group enhancement (not out-group disregard). J. Cogn. Neurosci. 23, 3343-3354. doi: 10.1162/jocn_a_00016

Zanna, M. P., Kiesler, C., and Pilkonis, P. A. (1970). Positive and negative attitudinal affect established by classical conditioning. J. Pers. Soc. Psychol. 14, 321-328. doi: 10.1037/h0028991

Conflict of Interest Statement: The authors declare that the research was conducted in the absence of any commercial or financial relationships that could be construed as a potential conflict of interest.

Received: 08 October 2014; accepted: 08 February 2015; published online: 24 February 2015.

Citation: Dang J, Xiao S and Mao L (2015) A new account of the conditioning bias to out-groups. Front. Psychol. 6:197. doi: 10.3389/fpsyg.2015.00197

This article was submitted to Evolutionary Psychology and Neuroscience, a section of the journal Frontiers in Psychology.

Copyright (C) 2015 Dang, Xiao and Mao. This is an open-access article distributed under the terms of the Creative Commons Attribution License (CC BY). The use, distribution or reproduction in other forums is permitted, provided the original author(s) or licensor are credited and that the original publication in this journal is cited, in accordance with accepted academic practice. No use, distribution or reproduction is permitted which does not comply with these terms. 